\title{
Change and Optimization of Landscape Patterns in a Basin Based on Remote Sensing Images: A Case Study in China
}

\author{
Chen Ying*, He Ling, Ha Kai \\ Institute of Land and Resources, Agricultural University of Hebei, \\ No. 289, Ling Yu Temple Street
}

Received: 12 January 2017

Accepted: 29 March 2017

\begin{abstract}
In this paper, Huailai County in China's Hebei Provice is considered an example for analyzing the characteristics of landscape patterns with three remote sensing datasets in 1995, 2005, and 2015. The land use change and landscape pattern of the study area were analyzed and it was found that from 1995 to 2015 , the area with the largest change of land use type was cultivated land and construction land. Results show an increasing landscape fragmentation in this area. Meanwhile, the connectivity presents a downward trend. In combination with the distribution of different landscape type patterns on the terrain niche and the functions of ecosystem services, a minimum cumulative resistance model was used to construct the landscape components of ecological sources, ecological corridors, and ecological nodes. The obtained dIIC and dPC show that river confluences and the surrounding area of the reservoirs are most important for landscape connectivity. Based on the above research, maintenance areas, restoration areas, enhancement areas, and protection areas of the landscape are divided, which will be useful for optimizing the ecological landscape.
\end{abstract}

Keywords: landscape pattern optimization, minimum cumulative resistance model, mountain basin area, Huailai County

\section{Introduction}

The optimal allocation of land resources is an effective approach to the sustainable use of land resources. Most research has focused on the allocation of land quantity and structure, and often aims at maximizing economic benefits [1], which neglects the influence of spatial pattern factors on ecological processes. We are facing increasingly serious ecological and environmental problems [2-3], and

*e-mail: chenying19998@qq.com the landscape pattern is more concerned with the influence of spatial pattern factors, which is closely related to the ecological process. The formation and development of the pattern are manifested from the spatial structure and quantity structure under the dual effects of natural and social factors, and profoundly affect the landscape function, and landscape processes and functional changes are also of interest to landscape ecology [4-6]. Landscape pattern optimization is based on a full understanding of landscape structure and landscape interaction, and by using the landscape ecology theory method (through pattern analysis and research), reasonable adjustment and configuration enhances landscape connectivity so that 
its function is more stable [7]. At present, research on landscape structure and function changes and ecological response is still immature, and most domestic and foreign landscape pattern optimization methods are conceptual models and mathematical models that cannot meet the theoretical guidance and requirements of landscape optimization. There are some limitations in specific applications [8-9]. GIS application makes the landscape elements and ecological processes achieve spatial simulation, but it lacks the effect of pattern optimization and evaluation of ecological impact. Knaapen et al. proposed the basis of the minimum cumulative resistance model (MCR) to optimize the landscape pattern, and the mathematical model and computer model of landscape pattern optimization based on the study of the relationship between the potential movement trend of the species and landscape pattern change, which can reflect the connectivity change of ecological flow, identify the ecological key points, and better reveal the influence between landscape pattern and ecological process - which is an effective way to optimize the landscape pattern [10]. The MCR model has been applied to species conservation, and many studies have constructed different types of landscape ecological security patterns based on this model [11-13]. With the deepening of research, this model has been applied in urban landscape planning, ecological function area division, fragmentation habitat optimization, and land use optimization [14].

The northwest mountain basin area is in the upwind area of Beijing, and its landscape pattern changes have great influence on the ecological environment of Beijing and even entire regions. Huailai county in this area is close to Beijing and strengthens coordination between Beijing and Tianjin. Huailai county, as an important ecological protection area around Beijing and Tianjin, plays an important ecological role. Huailai County is considered the research object in this paper, and the minimum cumulative resistance model is used to optimize the landscape pattern by remote sensing and GIS spatial analysis technology. The regional ecological environment will be improved and landscape ecological function will be enhanced.

\section{Material and Methods}

\section{Overview of the Study Area}

Huailai County is located in the southeastern part of the city of Zhangjiakou. It is $100 \mathrm{~km}$ away from the center of Beijing to the southeast. It lies at $115^{\circ} 16^{\prime}-115^{\circ} 58^{\prime} \mathrm{E}$ and $40^{\circ} 04^{\prime}-40^{\circ} 35^{\prime} \mathrm{N}$. The three types of landforms are plains, hills, and mountains. The elevation ranges from 320 to $1,954 \mathrm{~m}$, and the topography rises from the central basin to the north and south. The north and south mountains form a natural barrier for Huailai County, and Guanting Reservoir resides in the center of the basin. Rivers include the Haihe, and industrial and domestic sewage treatment requirements are higher, restricting the development of resources and industrial and agricultural production. The county is located in the rain-shaded area of northwest Hebei Basin. Precipitation is scarce, the weather is arid, the ecological environment is fragile and sensitive, the unused land is more, the land-carrying capacity is low, and the loess is covered with soil.

\section{Data Sources and Methods}

\section{Data Sources and Processing}

The data of this study include Landsat TM/ETM + remote sensing images of the county in 1995, 2005, and 2015. There are six kinds of landscape types in the area: cultivated land, garden land, forest land, construction land, water area, and unused land. The quadratic polynomial geometric correction of the remote sensing image in 2015 was carried out using ENVI 4.8 software to ensure that the corrected error was less than 0.5 pixels. Using the remote sensing image as a reference, the automatic registration of remote sensing images in 1995 and 2005 was completed by using the Image-to-Image module, and the classification of the remote sensing images was carried out by using supervised classification and humancomputer interaction. The results show that the overall accuracy of the classification results of three-phase remote sensing images is $85.79 \%, 85.84 \%$, and $87.13 \%$, respectively, which is different from those of three-phase remote sensing images. The accuracy of interpretation is more than $85 \%$, and accuracy accords with the research requirement.

\section{Research Methods}

\section{Remote Sensing Image Processing Method [15]}

The processing includes:

1. ENVI4.8 software for the original data for a variety of correction, projection conversion, border cutting, and other pretreatment.

2. The use of monitoring classification and unsupervised classification combined with visual interpretation from which to access land types of data.

3. Using cluster analysis to classify the post-processing in order to reduce the fragment image pattern and make the image smoother.

4. Through the field survey, combined with the current land use map and the support of Google Earth, using the ENVI4.8 software obfuscation matrix tool for accuracy evaluation, get confusion matrix report, calculate the Kappa coefficient of more than $85 \%$, and ensure that the accuracy of interpretation meets requirements.

\section{Landscape Pattern Index}

The landscape pattern index concentrates the landscape pattern information, which can reflect its simple structure and spatial configuration. CA, patch density (NP), mean patch area (AREA_MN), aggregation index 
(AI), and patch connectivity index (COHESION) were selected according to the need of the study. Landscape fragility (F), landscape shape index (LSI), landscape connectivity index (COHESION), Shannon's diversity index (SHDI), and degree of contagion (CONTAG) were selected at landscape level, landscape dominance (D), and area-perimeter fractal dimension (perimeter-area fractal dimension, PAFRAC). Three landscape pattern indices were calculated and analyzed by Fragstats 3.3, a landscape pattern analysis software.

\section{Topographic Index and Distribution Index}

The topographic index can be used to describe the effect of elevation and slope changes on landscape pattern [16], and the formula is shown as formula (1):

$$
T=\lg \left[\left(\frac{E}{\bar{E}}+1\right)\left(\frac{S}{\bar{S}}+1\right)\right]
$$

...where $T$ means topographic index; $E$ and $\bar{E}$ mean the elevation value of any point in the area and the average elevation value of the area where the point is located, respectively; and $S$ and $\bar{S}$ mean the slope value of the arbitrary point in the area and the average slope value of the area, respectively. The higher the elevation, the greater the slope point and the greater the terrain index; the elevation is higher but the slope is smaller or the elevation of the smaller slope of the higher point, the terrain index is located in the center.

To eliminate the dimensional effect of area differences, a distribution index is used to describe the distribution of different landscape types on the terrain gradient, as shown in (2):

$$
P=\left(\frac{S_{i e}}{S_{i}}\right) \times\left(\frac{S}{S_{e}}\right)
$$

...where $P$ is the distribution index, $e$ is the topographic factor, Sie is the $e$ area of the $i$-type landscape, $S i$ is the area of the $i$-type landscape, e is the total area, and $S e$ is the total landscape area under the specific terrain $e$ factor; $S$ is the entire area. The smaller the variation of the distribution index, the smaller the deviation of the landscape distribution from the standard distribution and the greater the suitability for the topographic difference. On the contrary, it shows that the landscape has a strong selectivity to the terrain [17]. When the distribution index $=1$, this shows that the proportion of a certain landscape in a terrain is greater than proportion of total area of landscape in the research area; when $>1$ it indicates a landscape in the terrain on the proportion of the total area of the landscape than the proportion of the study area, $>1$ is set as the dominant bit of the landscape type.

The distribution index of terrain position index (0.69 3.03) is superimposed on the three types of landscape types, and the distribution index of the three types of landscape types on these 10 topographic sections is calculated. The topographic position of distribution index $\mathrm{P}>1$ is defined as the dominant terrain bit interval.

\section{Evaluation of Ecological Service Function}

An important measure of landscape ecological function is ecosystem service function. In this study, we use Costanza's ecosystem service value model and Xie Gaodi et al. to formulate the regional ecosystem service value equivalent factor table (Table 1) for the regional correction coefficient (1.02) of Hebei Province [18], calculate the landscape of Huailai County in 2015 Ecological service value (Table 2), and grid-based processing, each grid size is $500 \mathrm{~m} * 500 \mathrm{~m}$, each grid to get the value of ecosystem services, the higher the value of ecological services, that is, the ecological function of the more high, the energy transfer between landscape units is easier, and the running resistance of landscape ecological flow is smaller [19].

Table 1. Ecosystem service value unit area in Huailai County (yuan/hm².a).

\begin{tabular}{|c|c|c|c|c|c|c|}
\hline Function & Arable land & Garden & Woodland & $\begin{array}{c}\text { Urban and } \\
\text { rural land }\end{array}$ & $\begin{array}{c}\text { Water } \\
\text { surface }\end{array}$ & $\begin{array}{c}\text { Unused } \\
\text { land }\end{array}$ \\
\hline Gas regulation & 446.74 & $1,921.10$ & $3,127.35$ & 0.00 & 0.00 & 0.00 \\
\hline Climate regulation & 795.22 & $1,608.36$ & $2,412.51$ & 0.00 & 410.99 & 0.00 \\
\hline Water conservation & 536.10 & $1,787.04$ & $2,859.25$ & 26.76 & $18,209.92$ & 26.76 \\
\hline Soil Formation and Protection & $1,304.56$ & $2,613.56$ & $3,484.72$ & 17.87 & 8.89 & 17.87 \\
\hline Waste treatment & $1,465.42$ & $11,70.56$ & $1,170.56$ & 8.89 & $16,244.25$ & 8.89 \\
\hline Biodiversity Conservation & 634.35 & $1,943.41$ & $2,912.87$ & 303.75 & $2,224.90$ & 303.75 \\
\hline Food production & 893.57 & $1,78.73$ & 89.37 & 8.89 & 89.37 & 8.89 \\
\hline Raw materials & 89.37 & $1,183.89$ & $2,323.14$ & 0.00 & 8.89 & 0.00 \\
\hline Entertainment culture & 8.89 & 589.72 & $1,143.70$ & 8.89 & $3,877.83$ & 8.89 \\
\hline Total & $6,174.22$ & $12,996.38$ & $19,523.47$ & 375.04 & $41,075.03$ & 375.04 \\
\hline
\end{tabular}


Table 2. Ecosystem services value of landscape types in Huailai County.

\begin{tabular}{|c|c|c|}
\hline Landscape type & $\begin{array}{c}\text { Value of Ecological } \\
\text { Service (10 thousand yuan) }\end{array}$ & $\begin{array}{c}\text { Value } \\
\text { Proportion }\end{array}$ \\
\hline Arable land & $15,101.38654$ & $8.11 \%$ \\
\hline Garden & $44,047.36861$ & $23.68 \%$ \\
\hline Woodland & $102,712.0163$ & $55.23 \%$ \\
\hline Construction land & 523.0852856 & $0.28 \%$ \\
\hline Water & $21,822.30124$ & $11.74 \%$ \\
\hline Unused land & $1,796.212717$ & $0.96 \%$ \\
\hline
\end{tabular}

\section{Minimum Cumulative Resistance Model}

The minimum cumulative resistance model (MCR) is the main consideration of the ecological model, which can be used to reflect the movement trend of the ecological source in the space. The minimum cumulative resistance (MCR) source, distance, and landscape characteristics of the base surface of the three factors [20-21] generate the basic formula:

$$
M C R=f \min \left(\sum_{j=n}^{i=m} D_{i j} \times R_{i}\right)
$$

...where $f$ is the positive correlation function between the minimum resistance value at any point in the space and the landscape base surface, Dij represents the spatial distance from source $\mathrm{i}$ to landscape unit $\mathrm{j}$, and $R i$ represents the resistance value of cell $i$.

\section{Importance Analysis of Ecological Function Critical Area}

Connectivity is an indicator of landscape function, and good connectivity can make better use of landscape ecological functions. The overall connectivity index (IIC) and the likelihood connectivity index $(P C)$ reflect the connectivity of the landscape and the importance of the key areas [22]. The important value of the key point $(d I)$ denotes the change of the landscape connectivity of the whole area after breaking or disappearing at this point. In this study, the importance of the key points $(d I)$ of the two indexes $I I C$ and $P C$ is chosen:

$$
d I(\%)=\frac{I-I_{r}}{I} \times 100
$$

... where $I$ means exponent value for all keys and $I r$ means index value of the remaining keys after the disappearance of a key point.

\section{Results and Discussion}

\section{Analysis of Land Use Change}

Huailai County, land use types are more, although the land use structure is more complex, but follow a certain law. In the past 20 years, the economic, social, and cultural development of Huailai County has developed rapidly, and various land use types have undergone various changes under the influence of various factors. Based on the interpretation of remote sensing images in Huailai County in 1995,2005 , and 2015, the land use types of Huailai County were statistically analyzed with the data conversion and spatial analysis function of the GIS platform (Table 3).

From the above data we can see that from 1995 to 2015 the main land use type area changes, during Huailai County land use type area change characteristics are as follows:

1. In the study period, the area of land use types showed the pattern of "three minus three increases," i.e., cultivated land, water area, and unused land area showed a decreasing trend, the area of cultivated land changed from $31,854 \mathrm{hm}^{2}$ reduced to $25,228 \mathrm{hm}^{2}$ in 2015 , the area reduced to $6,627 \mathrm{hm}^{2}$ while water and unused land area decreased by a small number, from 1995 to 2015, respectively, by $3,497 \mathrm{hm}^{2}$ and

Table 3. Summary of land use types in Huailai County in 1995, 2005, and 2015.

\begin{tabular}{|c|c|c|c|c|c|c|}
\hline \multirow{2}{*}{$\begin{array}{c}\text { Name of land } \\
\text { category }\end{array}$} & \multicolumn{2}{|c|}{1995} & \multicolumn{2}{c|}{2005} & \multicolumn{2}{c|}{2015} \\
\cline { 2 - 7 } & Area $\left(\mathrm{hm}^{2}\right)$ & $\begin{array}{c}\text { Proportion } \\
(\%)\end{array}$ & Area $\left(\mathrm{hm}^{2}\right)$ & Proportion $(\%)$ & Area $\left(\mathrm{hm}^{2}\right)$ & Proportion (\%) \\
\hline Water & $8,999.35$ & $5.05 \%$ & $6,695.82$ & $3.76 \%$ & $5,502.37$ & $3.08 \%$ \\
\hline Arable land & $31,854.31$ & $17.87 \%$ & $29,591.55$ & $16.60 \%$ & $25,227.69$ & $14.17 \%$ \\
\hline Woodland & $49,893.43$ & $27.99 \%$ & $50,249.64$ & $28.19 \%$ & $52,544.21$ & $29.48 \%$ \\
\hline Construction land & $7,293.08$ & $4.09 \%$ & $9,645.74$ & $5.41 \%$ & $13,921.05$ & $7.82 \%$ \\
\hline Garden & $28,257.18$ & $15.85 \%$ & $29,155.86$ & $16.36 \%$ & $31,678.65$ & $17.76 \%$ \\
\hline Unused land & $51,934.86$ & $29.14 \%$ & $52,893.61$ & $29.68 \%$ & $49,358.25$ & $27.69 \%$ \\
\hline Total & $178,232.22$ & $100.00 \%$ & $178,232.22$ & $100.00 \%$ & $178,232.22$ & $100.00 \%$ \\
\hline
\end{tabular}


2,577 $\mathrm{hm}^{2}$. Garden, woodland, and construction land is increasing year by year. The change in construction area is the greatest, and the change amount is 6,628 $\mathrm{hm}^{2}$ in 20 years. There is a small increase in the area of garden land and woodland.

2. In the range of change, the variation range of different land types is obvious. During the study period, the land use type with the largest change scope was construction land, which increased by $90.88 \%$ from 1995 to 2015 far exceeding the change range of other land types. The large increase of construction land was due to Huailai county socio-economic development and that the proportion of the urban population is rising. Second, there are large areas of water and cultivated land, water area in 20 years, a sharp reduction of $38.86 \%$, and changes in the second only to construction land, while arable land is reduced by nearly one-fifth. Garden land, woodland, and unused land changed little, which were $12.11 \%, 5.31 \%$, and $4.96 \%$ respectively.

\section{Analysis of Landscape Pattern}

\section{Analysis of Dynamic Change of Landscape Pattern at Different Levels}

The change of landscape pattern mainly refers to the change of landscape structure, and the different structural features reflect the difference of landscape function. From the perspective of landscape types (Table 4) from 1995 to 2015, plots of arable land decreased by 8,300.89 hectares while the plaque area increased by $8,143.75$ hectares due to the better economic benefits in Huailai County, arable land. In recent, years due to the strengthening of ecological protection policies in the county, the patch of woodland area in 2005-15 increased by 2,210.49 hectares; cities and towns continue to expand, and the increasing active economic activity has increased the area of construction land by $6,160.06$ hectares in 20 years. The water area has been reduced by 4,288.96 hectares over 20 years under the influence of human activities and natural environment, and the proportion is reduced to $44.67 \%$. Type-level patch density, mean patch area, and aggregation index are often used to characterize the degree of fragmentation in a given area [23]. During the period from 1995 to 2015 , the patch density of cultivated land and water area showed an increasing trend, and the mean patch area and aggregation index decreased, indicating that the degree of fragmentation of farmland and water area was increasing and the heterogeneity was increasing. The patch density and average patch area of construction land showed an increasing trend, indicating that the degree of fragmentation increased again, but the increase of aggregation index showed that the heterogeneity was decreased and the control effect on the whole landscape was enhanced.

Table 4. Landscape pattern index of landscape types in Huailai county from 1995 to 2015.

\begin{tabular}{|c|c|c|c|c|c|c|}
\hline \multirow{2}{*}{ Landscape type } & \multirow{2}{*}{ Year } & \multicolumn{5}{|c|}{ Landscape pattern index } \\
\hline & & $\mathrm{CA}\left(\mathrm{hm}^{2}\right)$ & PD (Quantity/hm²) & AREA_MN $\left(\mathrm{hm}^{2}\right)$ & AI & COHESION \\
\hline \multirow{3}{*}{ Arable land } & 1995 & $32,759.67$ & 1.23 & 39.45 & 86.14 & 98.36 \\
\hline & 2005 & $29,788.54$ & 1.35 & 33.41 & 84.76 & 97.33 \\
\hline & 2015 & $24,458.77$ & 1.47 & 31.76 & 84.76 & 97.07 \\
\hline \multirow{3}{*}{ Garden } & 1995 & $25,748.26$ & 1.76 & 9.57 & 69.50 & 93.24 \\
\hline & 2005 & $28,452.05$ & 1.67 & 9.56 & 72.87 & 93.17 \\
\hline & 2015 & $33,892.01$ & 1.99 & 8.25 & 73.00 & 92.27 \\
\hline \multirow{3}{*}{ Woodland } & 1995 & $50,370.65$ & 0.70 & 40.49 & 88.03 & 98.79 \\
\hline & 2005 & $50,399.01$ & 0.70 & 40.38 & 87.94 & 98.81 \\
\hline & 2015 & $52,609.50$ & 0.74 & 39.92 & 88.50 & 98.96 \\
\hline \multirow{3}{*}{ Construction land } & 1995 & $7,787.33$ & 0.82 & 6.28 & 63.86 & 87.32 \\
\hline & 2005 & $9,706.22$ & 0.90 & 6.04 & 66.48 & 85.03 \\
\hline & 2015 & $13,947.39$ & 1.25 & 5.52 & 67.10 & 81.96 \\
\hline \multirow{3}{*}{ Water } & 1995 & $9,601.74$ & 0.15 & 31.17 & 91.67 & 97.61 \\
\hline & 2005 & $6,350.42$ & 0.17 & 19.38 & 85.33 & 97.18 \\
\hline & 2015 & $5,312.79$ & 0.20 & 17.45 & 89.54 & 96.98 \\
\hline \multirow{3}{*}{ Unused land } & 1995 & $51,846.49$ & 1.50 & 19.37 & 80.21 & 97.23 \\
\hline & 2005 & $53,417.88$ & 1.53 & 18.64 & 80.37 & 97.12 \\
\hline & 2015 & $47,893.69$ & 1.79 & 14.99 & 78.18 & 96.58 \\
\hline
\end{tabular}


Patch density of forestland decreased slightly and mean patch area and aggregation index also increased slightly, which indicated that the degree of fragmentation was low and the landscape stability was strong; the patch density of unused land increased, and the block area decreased, indicating that the degree of fragmentation was increasing. The cohesion index (COHESION) of the patch indicates the connectivity of the natural state of the corresponding patch type, with the greatest patch connectivity being woodland, reaching 98.95 by 2015, while the cultivated land, garden land, construction land, water and unused land, and the cohesion index decreased, indicating that the connectivity of the five landscape types showed a decreasing trend. Therefore, it was necessary to enhance the connectivity of these five types of interconnections during optimization.

\section{Analysis on Dynamic Change of Landscape Pattern in Landscape}

From the landscape level (Table 5), the number of landscape patches increased by 1,665 , the fragmentation index increased from 5.44 to 6.38 , and the landscape shape index increased from 44.46 to 47.38 from 1995 to 2015 , indicating that the landscape was more fragmented and of irregular shape. The decline of the landscape cohesion index indicates that the overall connectivity is decreasing. The increase of diversity index reflects that the landscape is concentrated toward medium landscape elements, indicating that landscapes are more and more controlled by a few patch types. The decrease of the degree of spread indicates that the connectivity of dominance types in landscapes is decreasing and landscape fragmentation is intensifying. From the type of landscape map we can also intuitively see that the town continued to expand outward, showing a more fragmentation characteristics.

\section{Basis and Composition Determination of Landscape Pattern Optimization}

\section{Distribution of Landscape Types at Different Terrain Levels}

The low terrain area is mainly distributed in water, cultivated land, construction land, and garden land, with middle terrain area mainly distributed as unused land, and woodland is widely distributed in the high terrain position. The distribution patterns of the different landscape types on the topography are different from those in 1995-2015 (Fig. 1). The distribution index of the three periods showed a great change in the low terrain, and the maximum of the distribution index appeared in the second level terrain position, and then increased and then decreased, and the distribution index in the topography remained basically constant. The dominant position of arable land concentrated in the first level, to the second level on the terrain bit distribution index declined sharply in the 2-6 level, where there is a more stable transition, and in the fourth level there is a certain degree of volatility in the first six levels. And its distribution index gradually approached zero. From 1995 to 2015, the distribution index of forest land in the study area continued to increase with the increase of topographic level, and the distribution index of forest land in each year remained basically unchanged, indicating that the forest land landscape was relatively stable. In the mountainous and hilly region, the forest land has a strong adaptability in different terrain, and its advantage interval is kept at grade 5-10. The dominance position of the construction land continued to decrease with the increase of the topography level, the distribution of the dominant position concentrated in the 1-2 level, and the distribution index of the other levels in the same level with the change of the year showed a decreasing trend, but the change is not obvious. The distribution index of the garden plot showed first a fluctuation and then a low fluctuation in the terrain position of grade 1-6, and the distribution index curve of each year was roughly consistent. The dominance distribution range was 1-2, and increased to the 1-2 and 4.3 in 2015 , the distribution of unused land index curve showed a trend of increased first and then decreased, the dominance interval narrowed from 2-6 in 1995 to 2015 2-5, The dominant interval maximum appears at the third level.

\section{Analysis of Landscape Ecological Function Intensity}

The landscape ecological function of Huailai County was significantly different (Fig. 2). The ecological function of Guanting Reservoir and its surrounding landscape in the central valley basin area was the highest, and the ecological function of forest landscape control in the north, northeast, and south of Huailai county were high, and low-landscape features of the region are mainly northwestern and southwestern mountain and hilly areas of unused land and the central plains of urban construction land. The woodland landscape in the north and south sides of Huailai County and the waters in the central basin area play an important role in regulating the ecological balance of the whole area. However, due to the influence of natural

Table 5. Landscape pattern index in Huailai County.

\begin{tabular}{|c|c|c|c|c|c|c|c|c|}
\hline Year & NP & F & LSI & COHESION & SHDI & CONTAG & D & PAFRAC \\
\hline 1995 & 9,694 & 5.44 & 44.46 & 97.46 & 1.59 & 41.90 & 0.89 & 1.29 \\
\hline 2005 & 9,848 & 5.53 & 45.42 & 97.19 & 1.60 & 41.78 & 0.82 & 1.28 \\
\hline 2015 & 11,359 & 6.38 & 47.38 & 96.97 & 1.61 & 40.65 & 0.83 & 1.26 \\
\hline
\end{tabular}


a)

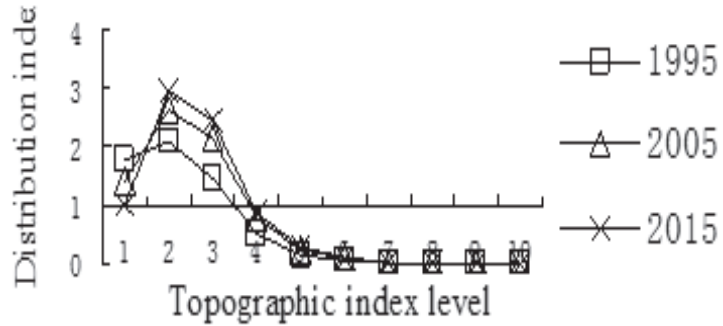

c)

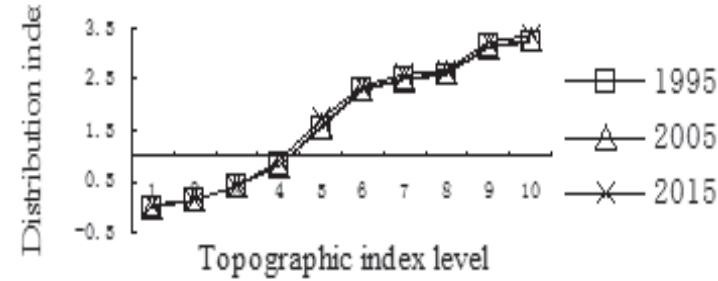

e)

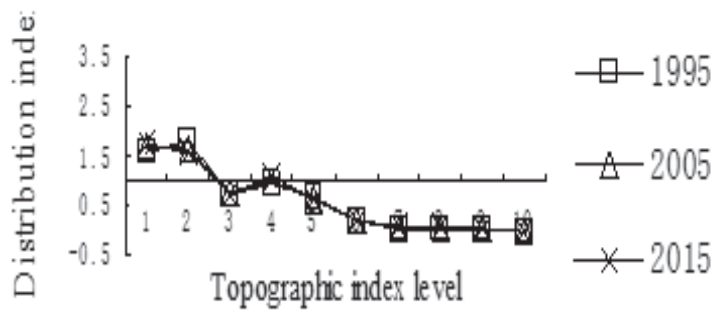

b)

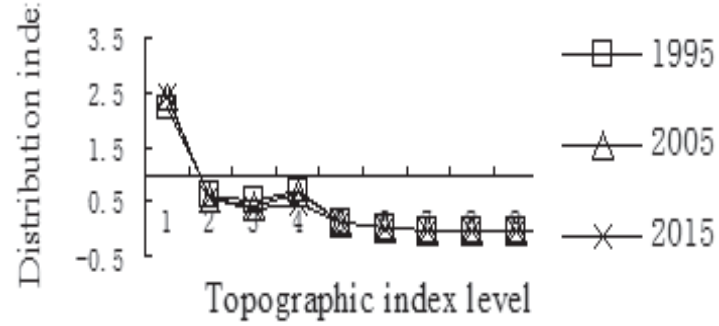

d)

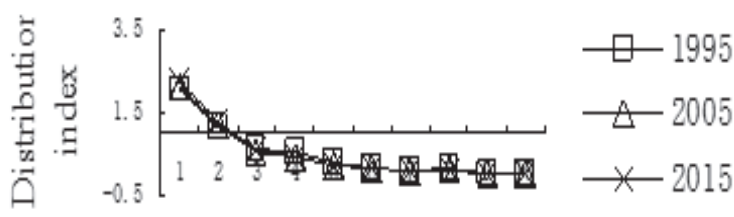

Topographic index level

f)

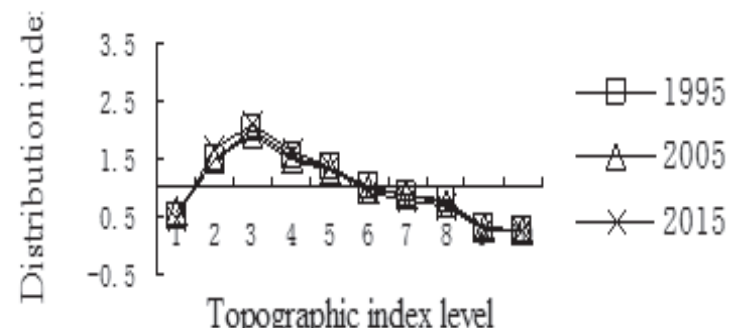

Fig. 1. Distribution of different landscape types on the terrain niche index in the study area. a) waters, b) cultivated land, c) woodland, e) land usde for building, e) garden plot, f) other land.

and manmade factors, the water area is shrinking, and landscape ecological function is stable. The construction and development of cities and towns occupy a large

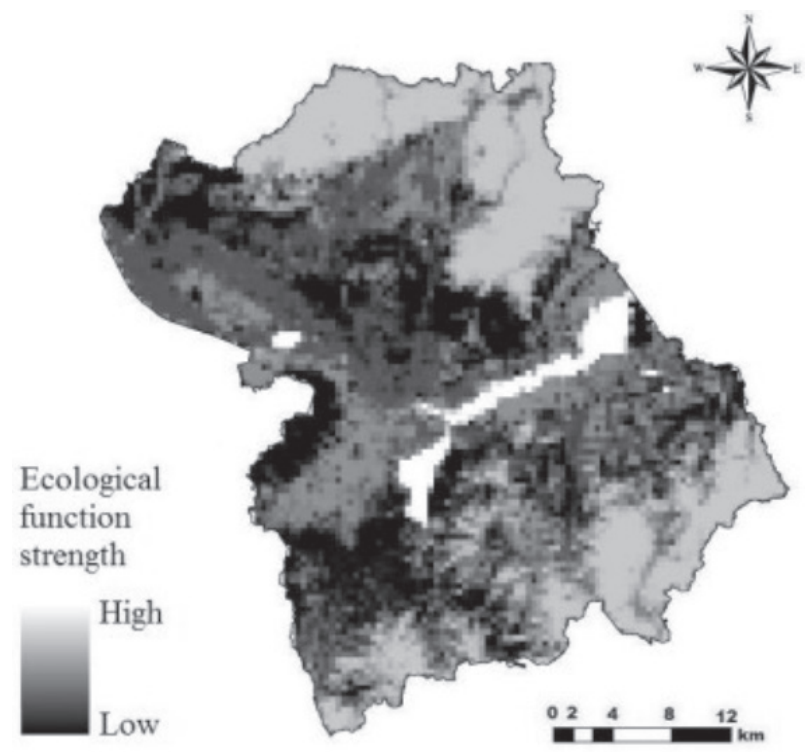

Fig. 2. Distribution of land use eco-function intensity in Huailai County. area of agricultural land so that the degree of fragmentation increases and the stability of the landscape is also reduced.

\section{Extraction of Ecological Source Area and Construction of Cost Distance Surface}

According to the theory of source-sink, the source landscape has the function of promoting the ecological process and maintaining ecosystem stability, and has continuity and expansibility in the space [24]. In order to protect the effectiveness, according to the distribution of ecological function intensity, considering the structure, quantity, and spatial topography of ecological sources, the forest patch with a core patch area larger than 100 hectares and the Guanting Reservoir in the central basin area were selected in mountainous hilly areas on the north and south sides. And the main rivers in the plain area are ecological sources (Fig. 3). These ecological sources are important to maintain regional ecosystem stability. They are the basic guarantee of regional ecological security and the ecological bottom line of urban expansion. They should be prohibited from development and construction, be included in the prohibited construction area, and set as the core protection area, the connectivity between the 


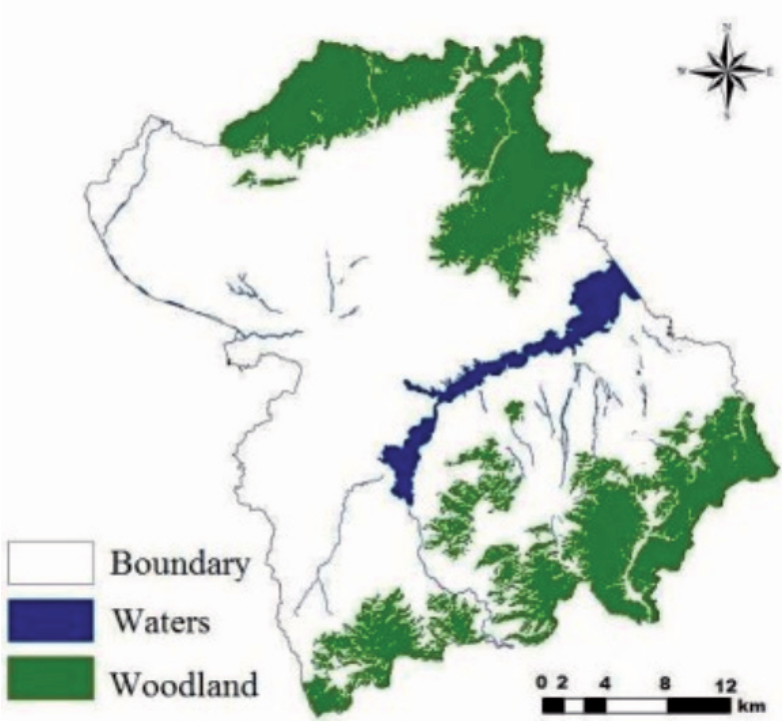

Fig. 3. Ecological land source in Huailai County.

various landscape patches, and the expansion of the core plaque area.

The cumulative distance reflects the spatial trend of the movement of source pixels, and its landscape ecology significance lies in from the pattern and process, through the spatial analysis of the landscape flow, to explore ways and methods conducive to emptying the ecological process, with a system in the direction of health, stability, and security. The source and resistance values are the basic data for constructing landscapes that consume distance surfaces. In theory, the higher the value of ecological services, the more perfect the ecological function of the landscape, the smaller the resistance of ecological flow, and the lower the resistance value (otherwise, the higher the resistance value). At the same time, because the study area is a typical mountainous and hilly area, topographic factors also play a key role in the operation of landscape

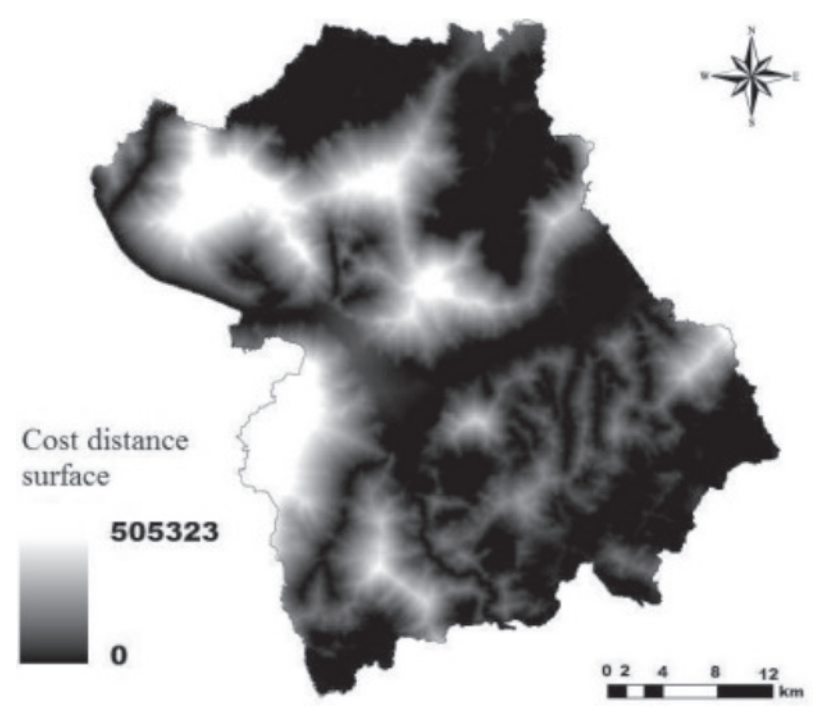

Fig. 4. Cost distance surface in Huailai County. ecological flow, and the topographic index can describe the influence of elevation and slope changes on landscape spatial pattern. Through landscape types, the resistance of the landscape ecological flow to the terrain position is determined. Based on the above two aspects, this study combines the ecological function intensity and ecological flow resistance value at different terrain levels to determine the final resistance value, and then construct the cost distance surface according to the minimum cumulative resistance model (Fig. 4).

\section{Extraction and Analysis of Ecological Corridor and Ecological Node}

The construction of the ecological corridor is the key to ensuring the connectivity between landscape units and promote the landscape ecological function. The shortest and longest path of ecological source diffusion is extracted according to the constructed distance-consuming surface, and the ecological corridor is obtained by screening the shortest consuming path. The intersection or shortest path of the shortest and longest consuming path is the potential ecological node. The corridor is generally linear or zonal and landscape elements, rivers, valleys, ridges, and forest corridor layout is the first choice. It can be seen from Fig. 5 that the Huailai ecological corridor is distributed in the higher fragmentation of the towns and Guanting Reservoir, as well as the main rivers along the road. Due to these areas of human activities being more intensive, the role of landscape plaques segmentation is more intense, and is a more intensive corridor area and also a corridor construction focus area and an ecological corridor that can weaken the division effect, maintain connectivity between plaques.

The ecological node is the node that plays a key role in the process of landscape ecological flow crossing different

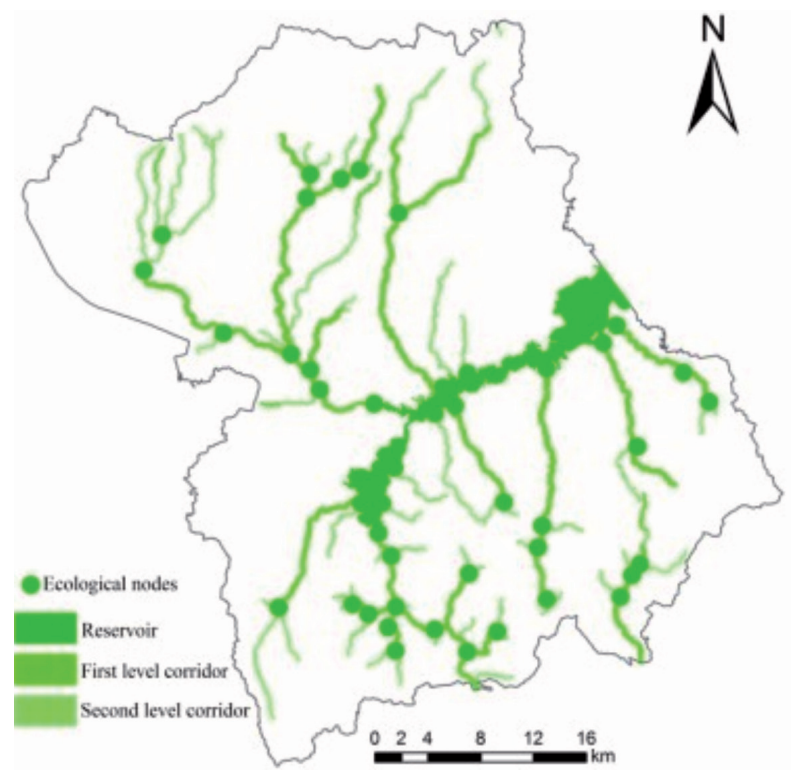

Fig. 5. Distribution of ecological corridor and node in Huailai County. 
landscape ecosystems. Cities around the reservoirs, wetlands, parks, or water interchanges, valley mouth, river floodplain, etc., can be used as ecological nodes. It can be seen from Fig. 5 that the ecological nodes of Huailai are concentrated in the water system interchanges of the north and south sides of Guanting Reservoir, the valley mouth, the floodplain, and the ponds and wetlands and woodland around the towns. In these areas landscape fragmentation is serious due to the interference of human factors, especially the rivers and the surrounding areas of the reservoir. It is not only the important area of ecological node distribution, but also the interaction area between landscape ecological flow and human disturbance. Ecological node is constructed and protected in order to fully guarantee the smooth flow of landscape ecology. For the surrounding areas of cities and towns, the ecological nodes are mainly located in the key sensitive areas of urban expansion, especially the interchanges between rivers and urban boundaries and roads. It is necessary to strengthen the protection of ecological nodes and set the buffer area.

\section{Evaluation of Ecological Nodes Importance}

The degree of connection between landscape components and their spatial effects play an important role in the maintenance and development of landscape functions [25]. From dIIC and dPC spatial distribution (Fig. 6), the two changes are similar to the connectivity of the key points that are mainly located in Guanting Reservoir and the surrounding Huailai County. From the importance of the ecological nodes, it is possible to distinguish the outflow and inflow of reservoir intakes such as the Yongding and Yanghe rivers, and the importance of the Yanghe and Sanggan rivers. The second is the ecology of the river intersections and valley node. At the same time, the importance of ecological nodes in the basin and plain areas is higher than that in hilly areas. Due to human activities, the fragmentation of the landscape around the reservoir in the basin area is becoming more and more serious. In addition, the ecological sensitivity of the area is high and the distribution density of the corridor is high, leading to the highest density and importance degree of the ecological node. At the same time, it is necessary to strengthen the protection of important ecological nodes in the transition zone between mountain ecosystem and basin ecosystem, reducing man-made destruction and interference, and ensuring the connectivity between the mountain basin ecosystems.

\section{Landscape Optimization Layout Partitioning}

Taking the topographic features of the study area into consideration, the spatial distribution of landscape pattern index, topographic index, and landscape ecological function intensity are taken into account, and the spatial distribution of ecological corridors and nodes is considered synthetically. The abrupt change of the resistance point curve, the obstruction of the unit where the
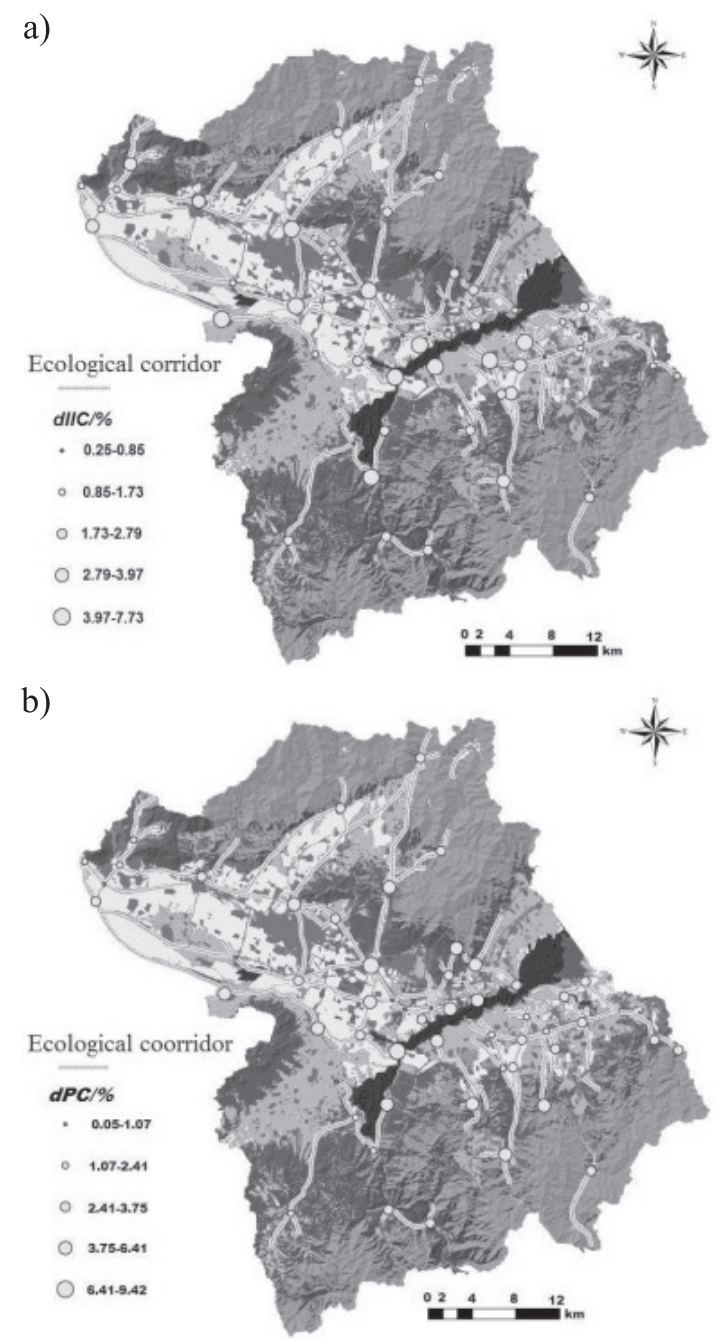

Fig. 6. Important values of integral connectivity a) dIIC, and possible connectivity b) dPC in ecological node area.

abrupt change point is located, or the sudden change of the stimulation effect indicates that some resistance changes abruptly to determine the pattern division finally, which are landscape ecological maintenance area, landscape ecological restoration area, landscape ecological function enhancement area, and landscape ecological function protection zone. The landscape ecological restoration area is a region with strong landscape ecological function but a high degree of landscape fragmentation. The landscape ecological restoration area is the landscape with the landscape ecological structure being stable and not having a significant impact on the regional ecological environment. And the landscape ecological function protection area is the strongest ecological function, which is the core area to guarantee the healthy development of a regional ecosystem.

The Huailai County landscape ecological maintenance area is mainly distributed in sand towns and other lowlying hilly areas of bare land and other unused land landscape types that are weak ecological services and ecological sensitivity of the region. For urban interior, green infrastructure construction should be emphasized, 
that is the green space can be protected, the ecological landscape network of biodiversity conservation, to limit the spread of urban disorder and expansion while maximizing the landscape pattern of the continuation of the region to strengthen the diversity of the edge And mosaic, to achieve the urban built-up area and the ecological edge of the diversity of the transition, as far as possible to avoid the rigid cutting of space caused by green infrastructure connectivity. As far as possible the introduction of agricultural landscape elements, an increase of integrated green space system, at the same time, the administrative and urban planning and land planning and others converge. In the hilly areas of bare land landscape the soil layer is thin and can be investigated and evaluated through the use of a variety of biological habitat regeneration technologies or engineering means targeted to improve vegetation coverage, prevent soil erosion and other ecological problems, and maintain the stability of ecological function.

The Huailai County landscape ecological restoration area is mainly located in the central plains and hilly areas, with farmland, orchard, and other agricultural landscapes, the terrain is more gentle due to the interference of human factors, such as a high degree of fragmentation of the landscape, and the change is more severe. The natural ecological corridor is not very developed and is mainly an ecological corridor. The area can be considered to design a semi-natural buffer zone to reduce the application of chemicals, improve the diversity of landscape and borders, and the protection of biological diversity of the channel will give priority to culverts, to strengthening farmland ecological network construction, shelterbelts, roads, and buffer zones, etc., to form a stable multi-level ecosystem network. In addition, the area is easy to be a highway, railway, and other traffic corridor cutting to broaden the width of the green belt on both sides of the road. If necessary, a culvert can be designed to increase the diversity of species in the green belt and enhance the connectivity between patches.

The distribution of the landscape ecological function enhancement area is the distribution of "mountain and water," which is the important connecting channel of a mountain basin system. In the "mountain" area, the construction of ecological green corridors should be strengthened, and the linear or zonal landscape elements such as rivers and shelter belts should be given priority as biological corridors. By using topography and linear landscape curves and surface habitats, habitat can be arranged by small ponds, trees, and other small patches as a mosaic to build a similar landscape to enhance landscape heterogeneity. In the Bangshui area there are many important ecological node areas where diversity of important node habitats should be increased as much as possible to increase vegetation coverage and diversity and to construct buffer zones and isolation zones to prevent human disturbance and environmental pollution.

We should pay attention to strengthening ecological construction, strictly control the expansion of construction land, and guide the natural patches to corridor or small patches in the form of scattered into the human activities more frequently in the construction land. At the same time, some natural vegetation patches are set around the construction land to realize the buffering and regulating effect on the ecological negative effect of human activities.

The landscape ecological protection area is mainly located in the central and southern rivers and lakes landscape type area and Zhongshan forest landscape type area, water area, and woodland area are major, as is the core area of ecological protection. For Guanting Reservoir and its main estuary areas, the construction of buffer zones along the coasts, wetlands, and reservoirs shall be protected and enhanced to provide the corridors and habitats for flooding, water quality, soil conservation, erosion reduction, wildlife, and insects. According to local natural conditions, the reconstruction of the hydrological environment is to prevent rain or surface runoff caused by the proliferation of pollutants. As a stable core area, the forest landscape of a mountainous area is an important biological habitat. The ecological system is perfect. The ecological landscape should be designed according to the composition of the food and landscape elements needed by the target species, and strict protection measures should be established to prevent artificial interference.

In summary, the four types of regions are not separate, but the complex ecological systems are linked together, and their artificial division is based on the characteristics of different regions to better characterize the distribution of landscape types, and design corresponding to a landscape optimization program services. For the actual landscape design you should also consider regional integrity and specificity.

\section{Conclusions}

1. From 1995 to 2015, the landscape pattern of Huailai County showed a trend of fragmentation and decreased connectivity, and the stability of the landscape pattern was reduced. The plaque area of cultivated land and other landscape types continued to decrease, and the heterogeneity and fragmentation of the landscape increased. The control effect of the few patch types on the landscape became more and more prominent, and landscape connectivity was reduced, to a certain extent, restricting ecological flow.

2. Using the minimum cumulative resistance model, the ecological corridors and ecological nodes of the study area were extracted and the ecological corridor was found to be distributed around the towns and Guanting Reservoir and the main rivers and roads. The ecological nodes were concentrated in Guanting Reservoir DIIC, and the $\mathrm{dPC}$ evaluation reflects the importance of ecological key areas, the key point being the greater connectivity of Guanting Reservoir, the river basin, around the water interchange, the valley mouth, the river floodplain, and Huailai County around the forest and river wetlands. 
3. The landscape ecological restoration area, the landscape ecological function enhancement area, and the landscape ecological function protection zone were divided into four areas, and the four types of areas were not separated, but the complex ecological relationship was an organically linked system and its artificial division is based on the characteristics of different regions to better characterize the distribution of landscape types, and the design of the corresponding landscape optimization services, the actual landscape design, you should also consider regional integrity and specificity.

\section{Acknowledgements}

This paper was supported by Social Science Foundation of Hebei Province (No. HB17GL054).

\section{References}

1. WU Q.X., YANG Y.F., ZHU L.Q. Trade-Off between structure and efficiency of land use in county scale. Economic Geography, 33, 147, 2013.

2. ZHAO X.Q., WANG H.B., YANG S.H., XU X.Y. GIS-based ecological optimization of spatial patterns of land resources. Acta Ecologica Sinica, 29, 4892, 2009.

3. YAN Y. Landscape Pattern Optimization in Mountains Area Based on GIS. Shandong Agricultural University, 2011.

4. LUO DING, XU YUE-QING, SHAO XIAO-MEI, WANG JING. Advances and Prospects of Spatial Optimal Allocation of Land Use. Progress in Geography, 28 (5), 791, 2009.

5. CHEN LI-DING, LIU YANG, LV YI-HE, FENG XIAOMING, FU BO-JIE. Landscape pattern analysis in landscape ecology: current, challenges and future. Acta Ecologica Sinica, 28 (11), 5521, 2008.

6. XIAO DU-NING, LI XIU -ZHEN, GAO JUN, CHANG YU, ZHANG NA, LI TUAN-SHENG. Landscape Ecology. Beijing: Science Press, 2006.

7. ZHANG LI, CHEN YAHENG, MEN MING-XIN, XU HAO. Assessing method for regional ecological connectivity and its application based on GIS. Transactions of the Chinese Society of Agricultural Engineering, 30 (8), 218, 2014

8. YUE DE-PENG, WANG JI-PING, LIU YONG-BING, XIE HUAICI, WANG DONGMEI. Landscape pattern optimization based on RS and GIS in northwest of Beijing. Acta Geographica Sinica, 62 (11), 1223, 2007.

9. CHEN LI-DING, LIU YANG, LV YI-HE, et al. Landscape pattern analysis in landscape ecology: current, challenges and future. Acta Ecologica Sinica, 28 (11), 5521, 2008.

10. XIAO DU-NING, LI XIU-ZHEN, GAO JUN, et al. Landscape Ecology. Beijing: Science Press, 2006.

11. ZHANG LI, CHEN YAHENG, MEN MINGXIN, et al. Assessing method for regional ecological connectivity and its application based on GIS. Transactions of the Chinese Society of Agricultural Engineering, 30 (8), 218, 2014.

12. YUE DE-PENG, WANG JI-PING, LIU YONG-BING, et al. Landscape pattern optimization based on RS and GIS in northwest of Beijing. Acta Geographica Sinica, 62 (11), 1223, 2007.
13. LIU JIE, YE JING. A GIS-Based landscape pattern optimization approach for Lake Dianchi watershed. Journal of Natural Resources, 27 (5), 801, 2012.

14. YE YU-YAO, SU YONG-XIAN, ZHANG HONG-OU, WU QITAO, LIU KAI. Ecological resistance surface model and its application in urban expansion simulations. Acta Geographica Sinica, 69 (4), 485, 2015.

15. YU KONG-JIAN, WANG SI-SI, LI DI-HUA. The function of ecological security patterns as an urban growth framework in Beijing. Acta Ecologica Sinica, 29 (3), 1189, 2009.

16. WEN BO, LIU YOU-ZHAO, XIA MIN. Layout optimization of rural residential land based on theory of landscape security pattern. Transactions of the Chinese Society of Agricultural Engineering, 30 (8), 181, 2015.

17. LI SUI, SHI TIE-MAO, FU SHI-LEI. Landscape ecological security pattern during urban expansion of Nanchong City. Chinese Journal of Applied Ecology, 22 (3), 734, 2011.

18. XIE GAO-DI, LU CHUN-XIA, LENG YUN-FA, ZHENG DU, LI SHUANG-CHENG. Ecological assets valuation of the Tibetan Plateau. Journal of Natural Resources, 18 (2), 189, 2005.

19. CHEN YING, XU HAO,CHEN YAHENG, MEN MINGXIN. Analysis of land function transformation and functional classification in county based on remote sensing image. Transactions of the Chinese Society of Agricultural Engineering (Transactions of the CSAE), 30 (13), 263, 2016.

20. LI HUI, YI NA, YAO WEN-JING, WANG SIQI,LI ZHIYING,YANG SHUHUA. Shangri-La county ecological land use planning based on landscape security pattern. Acta Ecologica Sinica, 31 (20), 5928, 2011.

21. GONG WEN-FENG, YUAN LI, FAN WEN-YI. Analysis on land use pattern changes in Harbin based on terrain gradient. Transactions of the Chinese Society of Agricultural Engineering, 29 (2), 250, 2015.

22. WU JIAN-SHENG, ZHANG LI-QING, PENG JIAN, FENG ZHE, LIU HONGMENG,HE SHENGBIN. The integrated recognition of the source area of the urban ecological security pattern in Shenzhen. Acta Ecologica Sinica, 33 (13), 4125, 2015.

23. SUN XIAN-BIN, LIU HONG-YU. Effects of land use change on wetland landscape connectivity and optimization assessment of connectivity - A case study of wetlands in the coastal zone of Yancheng, Jiangsu. Journal of Natural Resources, 25 (6), 892, 2010.

24. LI HUI, YI NA, YAO WEN-JING, et al. Shangri-La county ecological land use planning based on landscape security pattern. Acta Ecologica Sinica, 31 (20), 5928, 2011.

25. LI PING-XING, CHEN DONG, FAN JIE. Research of ecological occupiability based on least-cost distance model - A case study on Xijiang river economic belt in Guangxi. Journal of Natural Resources, 26 (2), 227, 2011.

26. WU JIAN-SHENG, ZHANG LI-QING, PENG JIAN, et al. The integrated recognition of the source area of the urban ecological security pattern in Shenzhen. Acta Ecologica Sinica, 33 (13), 4125, 2015.

27. KONG LING-HUA. Study on Landscape Heterogeneity of Mountainous and Hilly Region in the Middle-lower Yellow River. Henan University, 2015.

28. CHEN LI-DING, FU BO-JIE, ZHAO WEN-WU. Sourcesink landscape theory and its ecological significance. Acta Ecologica Sinica, 26 (5), 1444, 2006.

29. SUN XIAN-BIN, LIU HONG-YU. Optimization of wetland landscape patterns based on ecological function evaluation:a case study on the coastal wetlands of Yancheng, Jiangsu Province. Acta Ecologica Sinica, 30 (5), 1157, 2010. 